Conflict of Interest: The authors of this paper have no conflicts of interest, including specific financial interests, relationships, and/or affiliations relevant to the subject matter or materials included.

\section{References}

1. Yang JY, Chan AK. Pediatric thrombophilia. Pediatr Clin North Am 2013;60:1443-1462.

2. Biss T. Pulmonary embolism in childhood: how can we be sure not to miss it? Arch Dis Child 2018:103:814-816.
3. Aguiar CL, Soybilgic A, Avcin T, Myones BL. Pediatric antiphospholipid syndrome. Curr Rheumatol Rep 2015;17:27.

4. Rumsey DG, Myones B, Massicotte P. Diagnosis and treatment of antiphospholipid syndrome in childhood: a review. Blood Cells Mol Dis 2017;67:34-40.

5. Groot N, de Graeff N, Avcin T, Bader-Meunier B, Dolezalova P, Feldman B, Kenet G, Koné-Paut I, Lahdenne P, Marks SD, McCann L, Pilkington CA, Ravelli A, van Royen-Kerkhof A, Uziel Y, Vastert SJ, Wulffraat NM, Ozen S, Brogan $P$, Kamphuis $S$, Beresford MW. European evidence-based recommendations for diagnosis and treatment of paediatric antiphospholipid syndrome: the SHARE initiative. Ann Rheum Dis 2017;76:1637-1641.

\title{
Pediatric Chronic Myeloid Leukemia Presenting in a Mixed Phenotypic Blast Crisis: A Rare Occurrence
}

\author{
Bir Karışık Fenotipik Blast Krizinde Pediatrik Kronik Myeloid Lösemi Sunumu: \\ Nadir Bir Durum
}

\author{
(D) Jenna Bhattacharya, (D) Richa Gupta \\ Maulana Azad Medical College, Department of Pathology, New Delhi, India
}

\section{To the Editor,}

Pediatric chronic myeloid leukemia (CML) comprises 3\% of childhood leukemia cases [1]. Similar to adults, most of the patients present in the chronic phase, but 5\% may present in a blast crisis (BC) [2]. Mixed phenotypic $\mathrm{BC}$ has rarely been reported in children [3]. A 10-year-old male presented with fever, fatigue, dull abdominal pain, and massive splenomegaly for 2 months. Complete blood count results were as follows: total leukocyte count (TLC), 544×109/L; hemoglobin, $8 \mathrm{~g} / \mathrm{dL}$; and platelet count, $80 \times 109 / \mathrm{L}$. Differential count on peripheral smear revealed the following: blasts - $25 \%$, promyelocytes - 3\%, myelocytes - 20\%, metamyelocytes - 10\%, eosinophils - 5\%, basophils - 4\%, monocytes - 2\%, lymphocytes - $16 \%$, and neutrophils $-15 \%$. No dysplasia was noted. The blasts had moderate cytoplasm and prominent nucleoli. On cytochemistry, these blasts were negative for myeloperoxidase and periodic acid-Schiff. Bone marrow aspirate revealed a hypercellular marrow with myeloid predominance (M:E ratio of 25:1) with $55 \%$ blasts. Megakaryocytes were adequate with some dwarf forms. Bone marrow biopsy was hypercellular with near total replacement of marrow spaces with sheets of blasts having vesicular nuclei and prominent nucleoli (Figure 1). Blasts were positive for CD34, anti-MPO, CD19, and CD20 (Figure 1) and negative for CD3. Considering the high TLC and peripheral blood and bone marrow picture, RT-PCR for $M-B C R-A B L 1$ was done, which confirmed the presence of a 210-kDa transcript. Considering the clinical presentation, the peripheral blood picture (basophilia, many myelocytes and metamyelocytes), and the 210-kDa BCR-ABL1 transcript, a diagnosis of mixed phenotypic $B C$ in CML was issued and treatment was initiated with imatinib. Subsequently, the patient improved with lowering of TLC and disappearance of blasts from the peripheral blood. However, molecular response in follow-up could not be determined due to economic constraints.

The incidence of progression to BC in adults is 10\% but the same is not well known in children [3]. BC is usually myeloid and rarely mixed phenotypic [4]. The biology of progression of pediatric CML to $B C$ is supposed to be similar to that of adults [2]. Accumulation of additional chromosomal anomalies in the proliferating clone, especially deletions in the $C D K N 2 A / B$ gene, deletions in the IKZF gene, and chromosomal aberrations associated with myelodysplasia, have been implicated with progression [5]. Mixed phenotypic BC in CML needs to be differentiated from de novo mixed phenotypic acute leukemia (MPAL). Differentiation may be difficult since MPAL can also show $M-B C R-A B L 1$ translocation [6]. The points in favor of 

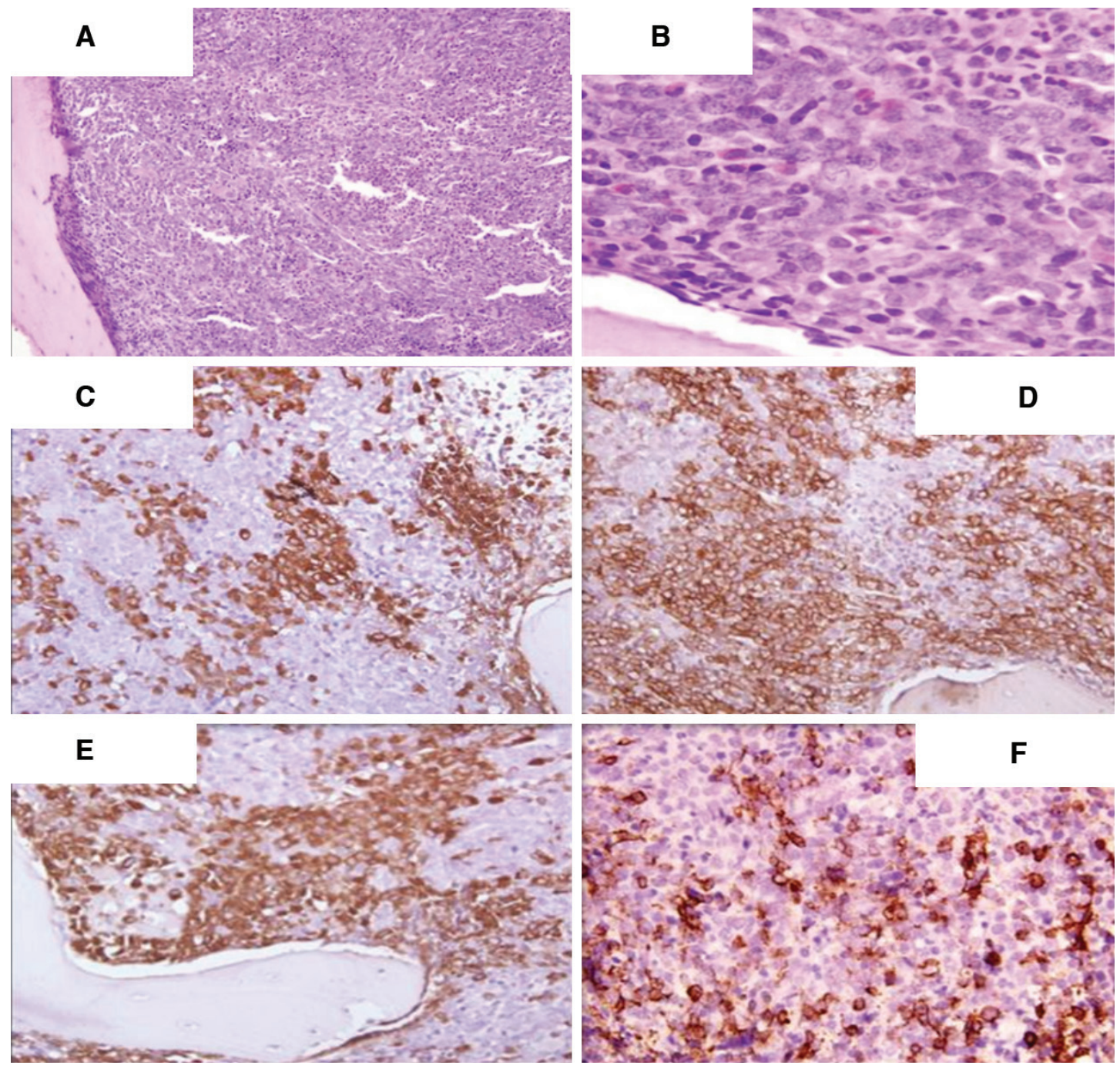

Figure 1. A) Bone marrow (BM) biopsy showing hypercellular marrow, H\&tE, 100x; B) BM biopsy showing blasts with prominent nucleoli, HEEE, 400x; C) BM biopsy showing CD34 positivity in blasts, 400x; D) BM biopsy showing anti-MPO positivity in blasts, 400x; E) BM biopsy showing CD19 positivity in blasts, 400x; F) BM biopsy showing CD20 positivity in blasts, 400x.

CML include high TLC at presentation, massive splenomegaly, peripheral blood basophilia and all myeloid precursors, absence of dysplasia, and the 210-kDa transcript on PCR. In such cases, if $M-B C R-A B L 1$ fusion signals are detected by FISH/PCR in mature neutrophils as well as in blasts (present in our case), then CML-BC is the most likely diagnosis [3]. Moreover, in a case of MPAL, if post-induction RT-PCR shows a high number of ablbcr transcripts despite reduction in blast count, the diagnosis of $\mathrm{BC}$ in $\mathrm{CML}$ should be considered. The progression to blast phase warrants a poor prognosis in $C M L$, which is further worsened by the presence of the mixed phenotypic type of BC [3]. Such cases should be treated with tyrosine kinase inhibitors plus chemotherapy based on the blast phenotype $[4,7]$.

Keywords: Pediatric, Chronic myeloid leukemia, Blast crisis

Anahtar Sözcükler: Pediatrik, Kronik myeloid lösemi, Blast kriz
Informed Consent: Received.

Conflict of Interest: The authors of this paper have no conflicts of interest, including specific financial interests, relationships, and/or affiliations relevant to the subject matter or materials included.

\section{References}

1. Millot F, Traore P, Guilhot J, Nelken B, Leblanc T, Leverger G, Plantaz D, Bertrand $Y$, Bordigoni $P$, Guilhot F. Clinical and biological features at diagnosis in 40 children with chronic myeloid leukemia. Pediatrics 2005;116:140-143.

2. Iyer $P$, Carney $P$, Bown N, Samarasinghe S. Pediatric chronic myeloid leukemia with B-cell lymphoid blast crisis at presentation. Blood Res 2013;48:149-163.

3. Choi W, Kim M, Lim J, HanK, Lee S, Lee JW, Chung NG, Kim Y. Four cases of chronic myelogenous leukemia in mixed phenotype blast phase at initial presentation mimicking mixed phenotype acute leukemia with $\mathrm{t}(9 ; 22)$. Ann Lab Med 2014;34:60-63. 
4. Gong Z, Bai S, Hu S. Mixed phenotype blast phase of chronic myeloid leukemia in the era of tyrosine kinase inhibitor therapy. Blood J 2016;128:5438.

5. Neuendorff NR, Burmeister T, Dörken B, Westermann J. BCR-ABL-positive acute myeloid leukemia: a new entity? Analysis of clinical and molecular features. Ann Hematol 2016;95:1211-1221.

6. Millot $F$, Baruchel A, Guilhot J, Petit A, Leblanc T, Bertrand $Y$, Mazingue $F$, Lutz $P$, Vérité $C$, Berthou $C$, Galambrun C, Bernard F, Yacouben $K$, Bordigoni P, Edan C, Reguerre Y, Couillault G, Méchinaud F, Cayuela JM, Guilhot F.
Imatinib is effective in children with previously untreated CML in early chronic phase: results of the French national phase IV trial. J Clin Oncol 2011;29:2827-2832.

7. de la Fuente J, Baruchel A, Biondi A, de Bont E, Dresse MF, Suttorp M, Millot F; International BFM Group (iBFM) Study Group Chronic Myeloid Leukaemia Committee. Managing children with chronic myeloid leukaemia (CML): recommendations for the management of CML in children and young people up to the age of 18 years. Br J Haematol 2014;167:33-47.

๑Copyright 2019 by Turkish Society of Hematology

Turkish Journal of Hematology, Published by Galenos Publishing House

\section{Myeloid Sarcoma of the Parotid Gland and Stomach Presenting with Obstructive Jaundice: A Rare Presentation}

\section{Obstrüktif Sarılık ile Başvuran Parotis Bezi ve Midenin Myeloid Sarkoması: Nadir Bir Sunum}

(D) Sugeeth M. Thambi1 ${ }^{1}$, (D Sreejith G. Nair ${ }^{1}$, (D) Rony Benson¹, (D) Jayasudha A. Vasudevan², (D) Rekha A. Nair²

1 Regional Cancer Centre, Department of Medical Oncology, Thiruvananthapuram, India

${ }^{2}$ Regional Cancer Centre, Department of Pathology, Thiruvananthapuram, India

To the Editor,

Myeloid sarcoma (MS) is the extramedullary deposit of immature myeloid cells and disrupts the normal tissue architecture [1]. MS commonly occurs in the skin, central nervous system, eyes, and testes. Gastrointestinal involvement is common $[2,3]$. Here we present a case of isolated MS of the parotid and stomach presenting with jaundice.

A 55-year-old male was evaluated with swelling of the right parotid gland for two months. Fine-needle aspiration was suggestive of a parotid neoplasm and the patient underwent a right-sided total parotidectomy. Post-op histopathological examination was suggestive of non-Hodgkin's lymphoma. While the patient was recovering, he developed jaundice. Liver function tests showed bilirubin of $5.3 \mathrm{mg} / \mathrm{dL}$ (direct: $4.2 \mathrm{mg} / \mathrm{dL}$ ). Contrast-enhanced computed tomography of the neck, chest, and abdomen was performed, which showed irregular soft tissue thickening in the parotid bed along with an enlarged enhancing left level IB nodal area $(21 \times 12 \mathrm{~mm})$. The abdomen showed intrahepatic biliary radicle dilatation with a soft tissue nodule at the porta. There was also soft tissue thickening involving the cardia and lesser curvature of the stomach along with multiple enlarged perigastric nodes (Figure 1).

Peripheral smear and bone marrow studies were normal. Review of the parotidectomy specimen showed a neoplasm composed of atypical medium to large cells. Tumor cells were myeloperoxidase-positive, CD33-positive, CD43 focalpositive, and CD68-negative and were compatible with MS (Figure 2). During work-up bilirubin increased to $20 \mathrm{mg} / \mathrm{dL}$ and the patient underwent percutaneous transhepatic biliary drainage. Upper gastrointestinal endoscopy was suggestive of mucosal irregularity involving the cardia and lesser curvature of the stomach. Endoscopic guided biopsy from the lesion was suggestive of MS. The patient's bilirubin normalized after stenting.

The patient was scheduled for $7+3$ induction ( 7 days of cytarabine at $100 \mathrm{mg} / \mathrm{m}^{2}$ as a 24-hour infusion along with 3 days of daunorubicin at $60 \mathrm{mg} / \mathrm{m}^{2}$ ). Post-induction reevaluation was done and contrast-enhanced computed tomography showed no significant lymph nodes, with significant reduction in the gastric and duodenal wall thickening along with resolution of the intrahepatic biliary radicle dilatation. The patient was scheduled for consolidation with high-dose cytarabine and received 3 cycles. He remained on follow-up after the completion of 3 cycles.

Isolated MS usually does not produce any specific symptoms besides the local symptoms of the organ involved. Local imaging is usually warranted in the form of computed tomography or magnetic resonance imaging [4]. Bone marrow study is also warranted to confirm isolated MS as 